\title{
Investigação da variabilidade interanual e interdecenal do clima do estado do Amazonas
}

\author{
Interannual and Interdecadal variability research of weather amazonas state \\ Fellipe Pereira da Silva1, José Ivaldo Barbosa de Brito2 e Gabrielle Bezerra Oliveira \\ fellipeh_maya@hotmail.com; jibdebrito@yahoo.com.br; gabrielle.121@hotmail.com \\ Universidade Federal de Campina Grande, Campina Grande, Brasil \\ Data de submissão 2015-10-09 / Aceitar 2016-07-14
}

\begin{abstract}
Resumo
Verificar e identificar tendências, variabilidades interanuais e decenais do clima dos municípios de São Gabriel da Cachoeira, Parintins e Manicoré, municípios do Estado do Amazonas, constituíram-se nos principais objetivos deste trabalho. Usaram-se dados de precipitação e temperatura do ar das três estações meteorológicas da rede de estações do INMET, existentes nas localidades supracitadas, no período de 1961 a 2010. Utilizou-se como base metodológica o método de balanço hídrico proposto por Thornthwaite e Mather de 1957, em uma versão sequencial, para as estimativas anuais dos índices de umidade, aridez e efetivo de umidade. A análise harmônica de Fourier foi utilizada para verificar oscilações interdecenal e interanual do clima. Os resultados obtidos mostraram que as três localidades apresentam grande variabilidade interanual do clima, variando, em geral de semiárido a hiperúmido, possivelmente relacionada com os eventos El Niño, La Niña e gradiente de anomalia da temperatura da superfície do mar do Atlântico tropical. Também se observou variabilidade interdecenal, provavelmente decorrente das oscilações decenal do Pacífico e multidecenal do Atlântico. Não se verificou tendência de longo prazo do índice efetivo de umidade, ou seja, não ocorreram mudanças climáticas nos três municípios analisados.
\end{abstract}

Palavras-chave: balanço hídrico; classificação climática; Amazonas; São Gabriel da Cachoeira; Parintins; Manicoré.

\begin{abstract}
The objective of this search was to verify and identify trends, interannual and decadal climate variability in the municipalities of São Gabriel da Cachoeira, Parintins and Manicoré, on the State of the Amazonas. It was used a datasets of precipitation and air temperature of three weather stations. These datasets belongs to the network of INMET stations and contains data in the period between 1961 to 2010. It was used as a methodological basis, the water balance method proposed by Thornthwaite and Mather 1957, in a sequential version, for the annual estimates of humidity, aridity and humidity effective indices. The harmonic Fourier analysis was used to verify interdecenal and interannual climate oscillations. The results showed that the three locations presents a great interannual climate variability, ranging, generally, from the semiarid to hiper humid, possibly related to the El Niño, La Niña phenomena and anomaly gradient of SST on the tropical Atlantic. Also there was interdecenal variability, probably due to the ten-year fluctuations in the Pacific and the Atlantic multidecenal. There was no long-term trend of the actual moisture content, or did not occur climatic changes in the three analyzed municipalities.
\end{abstract}

Keywords: water balance; climatic classification; Amazonas; São Gabriel da Cachoeira; Parintins; Manicoré. 


\section{Introdução}

Estudos envolvendo variáveis meteorológicas tem se mostrado muito eficientes em diversas áreas do conhecimento científico. Ao longo dos anos, diversos pesquisadores em todo mundo têm voltado sua atenção, principalmente, para as variáveis meteorológicas importantes no estudo das mudanças climáticas, buscando conhecer variações das mesmas, tanto em escala global como regional e variabilidades interanuais e interdecenais (Freitas et al., 2013).

De acordo com Hare (1985), os impactos da variabilidade climática são mais sensíveis nas regiões semiáridas, devido à vulnerabilidade de seus ecossistemas, podendo levá-las a um estágio de desertificação ou até mesmo à condição de deserto, quando os seus recursos naturais não são utilizados de forma apropriada. Entretanto, Fearnside (2006) descreve que a variabilidade interanual do clima, juntamente com as ações antrópicas na Amazônia e as mudanças climáticas globais e regionais, são elementos chaves no desenvolvimento e/ou decaimento dos ecossistemas Amazônicos. Ainda conforme Fearnside (2006), a floresta amazônica tem uma série de ligações de retroalimentação e mudança climática que representa uma ameaça séria à existência da floresta e para a continuação de seus serviços ambientais e que o fenômeno El Niño causa secas na Amazônia que, por sua vez, provê condições para incêndios destrutivos. A propósito, os efeitos das mudanças globais e das variabilidades climáticas tem recebido atenção de centros de pesquisas em climatologia em todo o mundo. Vários modelos foram desenvolvidos com o objetivo de se prever o clima da Terra, como um todo, ou em determinada parte.

Para medir as flutuações do clima de determinada área para um período de tempo, Budyko (1974) sugeriu um índice correspondente à razão entre a evapotranspiração potencial e a precipitação pluviométrica, utilizado nos programas das Nações Unidas (ONU) para identificar as áreas agricultáveis da Terra sujeitas aos processos de desertificação (Hare, 1977). Salienta-se que o índice de Budyko é utilizado para análises climáticas de qualquer Bioma, inclusive da floresta amazônica. Neste contexto, Quispe (2013) utilizou o índice de Budyko para analisar a sensibilidade do clima do Brasil, incluindo a Amazônia, em cenários de aquecimento global.

Por outro lado, a equipe de peritos do ETCCDMI (Expert Team on Climate Change Detection, Monitoring and Indices) criada pela OMM (Organização Meteorológica Mundial) recomenda a análise de parte de 27 índices básicos baseados em dados diários de temperaturas máximas e mínimas e de precipitação total diária para estudo de variabilidade e mudanças climáticas (Santos e Brito 2007). Os índices climáticos de aridez (Ia), de umidade (Iu) e efetivo de umidade (Im), decorrentes do balanço hídrico de Thornthwaite e Mather (1957), têm sido utilizados para a classificação climática e são pouco usados em análise de mudanças e variabilidades climáticas, entretanto, são fundamentais, pois com base nestes índices é possível identificar climas de áridos a hiperúmidos. A propósito, Hare (1977) sugeriu que a ONU utilizasse o índice efetivo de umidade de Thornthwaite e Mather na elaboração de cartas de áreas susceptíveis aos processos de desertificação e savanização. É importante ressaltar que os índices de aridez e umidade de Thornthwaite e Mather só são obtidos após a realização do balanço hídrico, utilizando-se o método proposto por Thornthwaite e Mather (1957). Neste modelo, as variáveis de entrada são a evapotranspiração potencial e a precipitação. Portanto, no presente estudo utilizaram-se os índices Ia, Iu e Im para analisar a variabilidade do clima de três localidades do estado do Amazonas.

A presente pesquisa tem por objetivo principal verificar e identificar tendências, variabilidades interanuais e decenais do clima de três municípios do estado do Amazonas, um no setor sul (Manicoré), outro no norte (São Gabriel da Cachoeira) e o terceiro no centro-leste do Estado (Parintins). Para tanto foram estimados os índices anuais de aridez, umidade e efetivo de umidade, ano a ano, no período de 1961 a 2010. Usou-se o balanço hídrico sequencial de Thornthwaite e Mather (1957). Vale salientar que para obter um diagnóstico acurado e preciso do clima e de sua variabilidade em determinada região, é necessário contar com boas medidas da precipitação e ótimas estimativas da evapotranspiração potencial e real. Na ausência de medidas diretas de evapotranspiração, o que não é fácil e nem disponível, mesmo nas estações meteorológicas mais equipadas, sendo necessária sua estimativa por meio de outras variáveis, como temperatura, vento, umidade e insolação e, ainda, radiação recebida e emitida pela superfície. No presente trabalho, foi usada a estimativa de evapotranspiração potencial de Thornthwaite (1948) com a correção para temperatura do ar superior a 26,5OC. Manaus não foi escolhida, porque existe um grande número de trabalhos publicados mostrando a variabilidade climática da Capital do Amazonas, como, por exemplo, Santos et al. (2012), Oliveira et al. (2006) e Cutrim et al. (2000). Além disso, pretende-se relacionar os resultados obtidos com os eventos de El Niño, La Niña e TSM e relacionar os resultados com as oscilações decenal do Pacífico e multidecenal do Atlântico.

\section{Material e Métodos}

\section{Área de estudo:}

O Estado do Amazonas é a maior unidade federativa do Brasil, em território, com uma área de 1559 159,148 $\mathrm{km}^{2}$. É maior que as áreas da França, Espanha, Suécia e Grécia somadas. É maior que a Região Nordeste, com seus nove estados; e equivale a 2,25 vezes a área do 
estado norte-americano do Texas. É a segunda unidade federativa mais populosa da Região Norte do Brasil, com seus 3,8 milhões de habitantes em 2014, sendo superado apenas pelo Pará. No entanto, apenas dois de seus municípios possuem população acima de 100 mil habitantes: Manaus, a capital é sua maior cidade com dois milhões de habitantes em 2014, que concentra cerca de $60 \%$ da população do estado, e Parintins, com pouco mais de 110 mil habitantes. Seus limites são com o estado do Pará ao leste; Mato Grosso ao sudeste; Rondônia e Acre ao sul e sudoeste; Roraima ao norte; além da Venezuela, Colômbia e Peru ao norte, noroeste e oeste, respectivamente. Conforme dados do Instituto Brasileiro de Geografia e Estatística, a densidade demográfica equivale a 2,23 habitantes por quilômetro quadrado. Detém $98 \%$ de sua cobertura florestal preservada e um dos maiores mananciais de água doce do planeta, proveniente da maior rede hidrográfica do mundo. A hidrografia do estado, entretanto, sofre grande influência de vários fatores como precipitação, vegetação e altitude. Em geral, os rios amazonenses são navegáveis e formam sua maior rede de transporte. Possui o maior Índice de Desenvolvimento Humano (IDH) (empatado com o Amapá) e o maior PIB per capita entre todos os estados do Norte do Brasil. A Região Metropolitana de Manaus, com população superior aos 2,2 milhões de habitantes e sendo a maior em área territorial do mundo, é sua única região metropolitana.

$\mathrm{O}$ acesso ao Estado é feito, principalmente, via fluvial ou aérea. Apresenta um relevo relativamente baixo, já que $85 \%$ de sua superfície está abaixo de cem metros de altitude. No Brasil, país caracteristicamente tropical, o Amazonas é dominado pelo clima equatorial. As estações do ano apresentam-se bastante diferenciadas e o clima é caracterizado por elevadas temperaturas e altos índices pluviométricos, decorrente, principalmente, da proximidade do estado com a Linha do Equador. Isso também se deve às altas temperaturas, que acabam por provocar uma grande evaporação, transformando-as em chuvas. O regime pluviométrico apresenta índices superiores a $2.000 \mathrm{~mm}$ ao ano, sendo bastante elevados. Entre os meses de maio e setembro, há ocorrência de friagens no sul e parte do centro do estado.

Na vegetação do estado, sobressaem matas de terra firme, várzea e igapós. Toda essa vegetação faz parte da extensa e maior floresta tropical úmida do mundo: a Floresta Amazônica.

O Amazonas é banhado pela bacia hidrográfica Amazônica, a maior do mundo, com quase quatro milhões de quilômetros quadrados em extensão. O rio Amazonas que dá nome ao estado - é o principal de seus rios, com 7.025 quilômetros de extensão, desde sua Nascente, na Cordilheira dos Andes, no Peru, até a sua foz no Oceano Atlântico.

Mais especificamente, as áreas de estudo da presente pesquisa resume-se a três cidades do Estado do Ama- zonas: São Gabriel da Cachoeira, Parintins e Manicoré. São Gabriel da Cachoeira $\left(00^{\circ} 7^{\prime} 48^{\prime \prime}\right.$; ; $67^{\circ} 5^{\prime} 20^{\prime \prime}$ O; 90 m) é um município do extremo norte do estado. Dista 852 quilômetros de Manaus, capital do estado, e está às margens da Bacia do Rio Negro. É considerado um ponto estratégico do País. É o município com maior predominância de indígenas no Brasil, uma vez que nove entre dez habitantes são indígenas. Sua área é de 109.185 quilômetros quadrados, representando 6,95\% do território estadual. De acordo com estimativas do IBGE, sua população era de 42342 habitantes em 2014, fazendo deste o décimo-terceiro município mais populoso do estado. Segundo dados do Instituto Nacional de Meteorologia (INMET), a temperatura mínima registrada em São Gabriel da Cachoeira foi de $16,6^{\circ} \mathrm{C}$, ocorrida no dia 19 de julho de 1975 . Já a máxima foi de $39,0^{\circ} \mathrm{C}$, observada dia no 22 de setembro de 2002. O maior acumulado de chuva registrado na cidade em 24 horas foi de $179,5 \mathrm{~mm}$, em 30 de maio de 1973.

Parintins ( $02^{\circ} 37^{\prime} 40^{\prime \prime} \mathrm{S} ; 56^{\circ} 44^{\prime} 09^{\prime \prime} \mathrm{O} ; 27 \mathrm{~m}$ ) localiza-se a leste da capital do estado, distando desta cerca de 370 quilômetros. Sua população foi estimada em 2014 pelo IBGE em 110411 habitantes, sendo o segundo mais populoso do estado do Amazonas. Sua área é de 5 952,33 $\mathrm{km}^{2}$, representando $0,37 \%$ do estado do Amazonas. O município é conhecido, principalmente, por sediar o Festival Folclórico de Parintins, uma das maiores manifestações culturais preservadas da América Latina. Localiza-se à margem direita do rio Amazonas. A vegetação, típica da região amazônica, é formada por florestas de várzea e de terra firme, tendo, ao seu redor, um relevo composto por lagos, ilhotes e uma pequena serra. A principal forma de transporte entre Parintins e os demais municípios é o fluvial, além do aéreo. A temperatura média registrada é de $26^{\circ} \mathrm{C}$. O clima de Parintins é equatorial com pequeno período seco, entre os meses de agosto e outubro. Segundo dados do INMET, referentes ao período de 1967 a 1990 e a partir de 1993, a menor temperatura registrada em Parintins foi de $12,9^{\circ} \mathrm{C}$ em 2 de janeiro de 1975 , e a maior atingiu $39^{\circ} \mathrm{C}$ em 7 de janeiro de 1998. O maior acumulado de chuva em 24 horas foi de $173 \mathrm{~mm}$ em 29 de novembro de 1972. Em março de 1999 foi observado o maior volume total de chuva acumulado em um mês, de 773,3 mm, seguido pelos 709,2 mm em janeiro de 2013.

O município de Manicoré $\left(05^{\circ} 48^{\prime} 32^{\prime \prime} S ; 61^{\circ} 18^{\prime} 00^{\prime \prime} \mathrm{O}\right.$; $45 \mathrm{~m}$ ) pertence à mesorregião do Sul Amazonense e microrregião do Madeira. Sua população estimada em 2014 pelo IBGE era de 52.200 habitantes. Localiza-se a $333 \mathrm{~km}$ da capital do estado, à margem direita do rio Madeira. Segundo dados do INMET, a temperatura mínima registrada em Manicoré foi de $11,5^{\circ} \mathrm{C}$, ocorrida no dia 18 de julho de 1975 . Já a máxima foi de $38,5^{\circ} \mathrm{C}$, observada dia 21 de setembro de 2005. O maior acumulado de chuva registrado na cidade em 24 horas foi de 130,6 mm, em 2 de abril de 1973. 


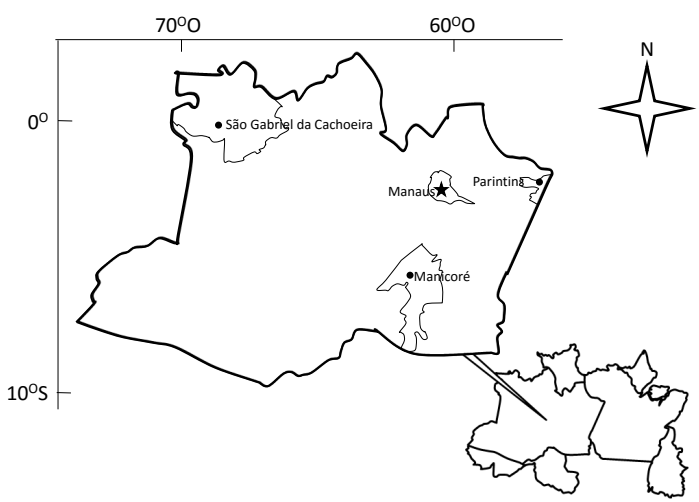

Figura 1: Localização geográfica do Estado do Amazonas, da capital Manaus e dos municípios São Gabriel da Cachoeira, Parintins e Manicoré, com marcações de Latitude e Longitude.

\section{Dados:}

Os dados utilizados no presente trabalho são acumulados diários de precipitação e de temperaturas mínimas e máximas diárias oriundas do INMET disponíveis de 1961 até 2010 para as localidades de São Gabriel da Cachoeira e Parintins e de 1971 até 2010 para o município de Manicoré. Tais dados foram disponibilizados pela rede de estações meteorológicas do INMET.

Havia lacunas na base de dados, onde, basicamente, não foram considerados os meses em que faltavam mais que três dias de dados de precipitação e cinco dias de dados de temperatura. $\mathrm{O}$ tratamento dos dados foi feito da seguinte forma: 1) média mensal dos dados de temperatura máxima e média mensal dos dados de temperatura mínima e, além disso, a média entre essas duas médias; 2) soma dos dados diários de precipitação objetivando a obtenção do acumulado mensal.

A partir da decisão de não considerar os meses com $10 \%$ ou mais com falha nos dados de precipitação e $17 \%$ ou mais com falhas nos dados de temperatura, lacunas pontuais surgiram, porém sem grande impacto para o estudo. Além das lacunas existentes por estes motivos, outros dados também estiveram faltando na base de dados. Nas três localidades, não existiam nenhum dado, nem de temperatura do ar nem de precipitação, para os anos de 1991 e 1992. Em Parintins, também não existiam dados para o ano de 2004. E para Manicoré, localidade com maior déficit de dados, estava faltando dados de precipitação para os anos de 1980 a 1982, 1990, 1991 e 1992. A decisão tomada para esses casos em que havia dados faltosos foi considerar tais valores iguais aos valores médios, visto que tal decisão não produziria variabilidade interanual artificial.

\section{Metodologia}

\section{Balanço Hídrico}

O balanço hídrico no solo pode ser determinado pela seguinte equação:

$$
E T_{r}=P_{r}+I_{r}-\Delta A_{s}-P_{\theta}-E_{s}
$$

Onde ETr é a evapotranspiração real; Pr é a precipitação; Ir é a água de irrigação; $\Delta$ As é a mudança de umidade no solo; Pe é a percolação e Es o escoamento superficial, dados em $\mathrm{mm}$ /período de tempo considerado.

Se a capacidade de armazenamento de umidade de um solo é conhecida, a equação do balanço hídrico pode ser resolvida pela comparação da precipitação e da água de irrigação com a evapotranspiração. $\mathrm{O}$ balanço hídrico por ser computado em escala de tempo diária, semanal ou mensal, o qual tem sido usado para resolver inúmeros problemas, tais como, o controle do intervalo de irrigação, planejamento dos recursos hídricos, previsão de rendimento de cultura, classificação climática, entre outros.

O balanço hídrico idealizado por Thornthwaite e Mather (1957) considera que o próprio solo oferece certa resistência às perdas de água para a atmosfera, e que esta aumenta com a redução da água armazenada no solo. $\mathrm{O}$ método também considera que quando ocorre, no período considerado, um saldo positivo entre a precipitação e a evapotranspiração potencial, este é incorporado ao solo, reabastecendo-o. Quando o solo atinge a sua capacidade de armazenamento pleno, esse saldo passa a ser considerado como excesso (escoamento e drenagem profunda). Este balanço de água tem como variáveis básicas de entrada a precipitação e a evapotranspiração potencial e como variáveis derivadas (saída); armazenamento de água no solo; variação do armazenamento de água do solo; negativo acumulado; evapotranspiração real; excesso e deficiência hídrica.

As variáveis negativo acumuladas (Nac.) e armazenamento de água no solo (As) são calculados simultaneamente para facilitar o fechamento do balanço. Os primeiros cálculos, para balanço hídrico anual com intervalo de tempo mensal, são iniciados pelo último mês do período chuvoso, ou seja, o último mês em que a precipitação (Pr) é superior a evapotranspiração potencial (ETp). Espera-se que nesse mês, denotado por j, o solo esteja plenamente abastecido de água, ou seja

$$
\left(N_{a c}\right)_{j}=0
$$

(As)j = lâmina de máximo armazenamento de água $(\mathrm{CA}=\mathrm{CAD})$

A partir do mês j+1, ou seja, no primeiro mês em que ocorre Nac, o solo começa a perder água. A água que está no solo é uma função de Nac e da máxima capacidade de água disponível e são dadas pelas seguintes expressões:

$$
\left(N_{a c}\right)_{j+1}=\left(N_{a c}\right)_{j}+\left(P_{r}-E T_{p}\right)_{j+1}
$$


$\left(A_{s}\right)_{j+1}=C A * \exp \left(\frac{\left(N_{a c}\right)_{j+1}}{C A}\right)$ (1980).

Conforme modificações sugeridas por Krishan

Após o período em que PR-ETp é menor que zero, ou seja, no primeiro mês em que (Pr-ETp) é positivo, inicia-se a reposição de água no solo. Nesses meses, o armazenamento de água no solo As é obtido adicionando ao valor de As do mês anterior ao valor de Pr-ETp do mês considerada, ou seja:

$$
\left(A_{s}\right)_{j}=\left(P_{r}-E T_{p}\right)_{j}+\left(A_{s}\right)_{j-1}
$$

Isto significa que a parte da precipitação que não foi consumida pela evapotranspiração do mês considerado, se junta ao armazenamento já existente do mês anterior. $\mathrm{Se}(\mathrm{As}) \mathrm{j}$ for menor do que CA, o (Nac)j é calculado pela seguinte equação, já incluída as modificações sugeridas $\left(N_{a c}\right)_{j}=C A * \ln \left(\frac{\left(A_{s}\right)_{j-1}}{C A}\right)$

Quando o resultado da equação 5 for igual ou superior à capacidade máxima de água disponível, o valor de (As) j será correspondente a essa capacidade e o excedente é considerado excesso, e o solo é considerado plenamente abastecido. Neste caso, (Nac)j é nulo. Nos casos em que após o período mais chuvoso (meses consecutivos em que (Pr-ETp) ๑ 0), a soma de (Pr-ETp) deste período for inferior a CA. Inicia-se o balanço no último mês em que (Pr-ETp)®0, denominado de mês k. (As)k é a soma (Pr-ETp) do período chuvoso e (Nac)k é calculado pela equação 6.

Quando, pelo procedimento acima, o valor do armazenamento do mês $k$, (As)k, não atinge a lâmina máxima considerada, deve-se repetir o balanço, partindo novamente do mês k com o valor de (As)k encontrado, o qual serve de base para a obtenção dos valores de A e B. Tal procedimento é repetido até que o valor de (As) $\mathrm{k}$ encontrado seja igual àquele utilizado para iniciar o balanço. O que significa fechar o balanço.

A variação da quantidade de água armazenada no solo ( $\triangle \mathrm{As}$ ) é sempre igual a As do mês j menos As do mês j-1.

A evapotranspiração real (ETr) é obtida da seguinte maneira:

a) nos meses em que a precipitação é inferior a evapotranspiração potencial ETr é dada por:

$$
\left(E T_{r}\right)_{j}=\left(P_{r}\right)+\left(\left|\Delta A_{s}\right|\right)_{j}
$$

b) nos meses em que a evapotranspiração potencial é menor ou igual a precipitação, ETr é dada por:

$$
\left(E T_{r}\right)_{j}=\left(E T_{p}\right)_{j}
$$

A deficiência hídrica (D) é dada por:

$$
D_{j}=-\left(E T_{r}\right)_{j}+\left(E T_{p}\right)_{j}
$$

O excesso (S) é dado por:

$$
S_{j}=\left(P_{r}-E T_{p}\right)_{j}-\left(\Delta A_{s}\right)_{j}+D_{j}
$$

Que corresponde ao excesso de precipitação que não foi absorvido pelo solo, por este já estar com sua capacidade de armazenamento plenamente atingida. Significa dizer que somente há excesso a partir do momento em que o armazenamento atinge a capacidade de água disponível.

De acordo com Zektser e Loaiciga (1993), a quantidade de água infiltrada (Pe), que abastece ou renova os lençóis subterrâneos, é aproximadamente de 10 \% a 15 $\%$ da água precipitada, evidentemente, esta percentagem depende do tipo de solo, da orografia, cobertura vegetal e da intensidade e duração da precipitação.

De posse do excesso hídrico, determina-se o escoamento superficial (Es) e a infiltração (Pe) da seguinte forma:

$$
\begin{aligned}
& \left(P_{\theta}\right)_{j}=\operatorname{krr}\left[0,4\left(S_{j}\right)+0,1\left(S_{j-1}\right)\right] \\
& \left(E_{s}\right)_{j}=S_{j}-\left(P_{\theta}\right)_{j}
\end{aligned}
$$

Onde, krr é igual à razão entre $1 / 2$ do excesso hídrico anual e $13 \%$ da precipitação anual, desde que $13 \%$ da precipitação anual seja superior a $1 / 2$ do excesso hídrico, caso contrário krr é igual a um.

Na equação original de Thornthwaite e Mather (1957), não havia o coeficiente krr, ou seja, este coeficiente era considerado igual a 1, mas, devido às observações de Zektser e Loaiciga (1993), de que a água infiltrada é aproximadamente $10-15 \%$ da água precipitada, optou-se por usar o fator de correção krr.

Caso seja observado que em todos os meses (Pr-ETp) foi menor que zero, o negativo acumulado não existe, o armazenamento é nulo, a evaporação real é igual a precipitação, a deficiência hídrica é (ETp - ETr) e o excedente é nulo.

Após a verificação dos resultados, calcularam-se os índices de aridez (Ia), umidade (Iu) e efetivo de umidade (Im) da seguinte maneira:

$$
\begin{aligned}
& I_{a}=100 * \frac{\Sigma D}{\Sigma E T_{p}} \\
& I_{u}=100 * \frac{\Sigma S}{\Sigma E T_{p}} \\
& I_{m}=I_{u}-0,6 * I_{a}
\end{aligned}
$$

Estes índices são úteis para a determinação do tipo de clima da região em estudo, pelo método de Thornthwaite Mather, bem como para o Zoneamento Climático, que é o estudo de adaptação de culturas à região. Tal qual a Tabela: 


\begin{tabular}{|c|c|c|}
\hline & Tipo de Clima & Índice de Umidade \\
\hline A & Hiperumido & Acima de 100 \\
\hline B4 & Umido & 80 a \\
\hline B3 & Umido & $60 \mathrm{a}$ \\
\hline B2 & Umido & $40 \mathrm{a}$ \\
\hline B1 & Umido & $20 \mathrm{a}$ \\
\hline $\mathrm{C} 2$ & Subúmido úmido & $0 \mathrm{a}$ \\
\hline $\mathrm{C} 1$ & Subúmido seco & $-20 a$ \\
\hline D & Semiárido & $-40 a-20$ \\
\hline E & Árido & $-60 a-40$ \\
\hline
\end{tabular}

Tabela 1 - Sistema de classificação climática proposta por Thornthwaite e Mather (1957)

\section{Estimativa da evapotranspiração potencial}

A evapotranspiração potencial foi estimada utilizando o método de Thornthwaite, que é uma das formas mais antigas de se avaliar a evapotranspiração. Este método baseia-se na temperatura média mensal e na duração efetiva do dia e não é apropriado para estimativas da evapotranspiração em curtos períodos de tempo, como semanas ou dias. Trata-se de uma técnica climatológica para o cálculo da evapotranspiração potencial mensal (mm/mês), que pode ser obtido da seguinte forma (Thornthwaite, 1948):

$E T_{p j}=C_{j} E_{j}=16 C_{j}\left(\frac{10 T_{j}}{I}\right)^{a_{1}}$

Em que ETpj é a evapotranspiração potencial do mês j, Cj é o fator de correção, que varia em função do número de dias do mês considerado (Dj) e da duração efetiva média desse dia $(\mathrm{Nj})$, obtidos, respectivamente, por:

$C_{j}=D_{j} \frac{N_{j}}{12} \quad$ e $N_{j}=\arccos \left(\frac{-\operatorname{tg} \phi \operatorname{tg} \delta}{15}\right)$

Em que $\phi$ é a latitude local; $\delta$ a declinação do Sol para o dia considerado dado por:

$\delta=0,409 \operatorname{sen}(0,0172 J-1,39)$

$\mathrm{J}$ - dia Juliano e $\delta$ em radiano

(Nj) é a insolação máxima teórica é calculada para o dia 15 de cada mês (j); Ta é a temperatura média mensal do ar $\left({ }^{\circ} \mathrm{C}\right)$ e a1 é função cúbica do índice anual de calor, dada por:

$a_{1}=6,75 * 10^{-7} I^{3}-7,71 * 10^{-5} I^{2}+1,79 * 10^{-2} I+0,4$

em que I é o índice de calor obtido pela soma dos 12 índices mensal (i), expressos por:
$I=\sum_{j=1}^{12} i_{j} ; i_{j}=\left(\frac{T_{a}}{5}\right)^{1,514}$

A equação 16 somente é válida quando a temperatura média do ar for inferior ou igual a $26,5^{\circ} \mathrm{C}$. Para temperaturas superiores a esse valor a ETp obtida deve ser multiplicado por um fator de correção (CT) dado por:

$C_{T}=1-e^{-\theta^{-\alpha\left(T_{j}-\beta\right)}}$

Sendo $\alpha$ e $\beta$ parâmetros de ajuste. Os valores de $\alpha$ e $\beta$ que melhor ajustam o coeficiente CT são, respectivamente, 0,28 e 33,1 .

\section{Análise harmônica}

As séries de Fourier são de grande importância tanto na Matemática abstrata como na Matemática aplicada. As Séries de Fourier são uma família de funções ortonormais que podem aproximar periodicamente com precisão arbitrária, funções com valores complexos. No século XVIII problemas físicos, como modelos de condução de calor e o estudo das vibrações e oscilações conduziam para o estudo da Série de Fourier.

Seja uma série temporal de dados de uma variável climatológica $\mathrm{f}(\mathrm{t})$, observado em um intervalo de tempo $\Delta \mathrm{T}$, durante um período $\mathrm{T}$, produzindo um número total de observações $\mathrm{N}$ igual a $\mathrm{T} / \Delta \mathrm{T}$. A variável $\mathrm{f}(\mathrm{t})$ pode ser representada por uma série trigonométrica dada por:

$f\left(t_{i}\right)=a_{0}+\sum_{k=1}^{K}\left(a_{k} \cos \left(k \omega t_{i}\right)+b_{k} \operatorname{sen}\left(k \omega t_{i}\right)\right.$

Em que ao é o coeficiente da série de Fourier conhecido por harmônico fundamental, representando a própria média aritmética da série de dados observados; k identifica o número de harmônicos que, para as séries analisadas, varia de 1 a $K$, sendo $K=N / 2$, para $N$ par, caso $\mathrm{N}$ seja impar $\mathrm{K}=(\mathrm{N}-1) / 2$; ak e bk coeficientes de cosseno e seno para o harmônico " $k$ " da séries de Fourier; $\omega$ frequência angular das ondas de Fourier, sendo $\omega=2 \pi / \mathrm{N}$; ti ordenação numérica das observações correspondentes da série $(i=0,1, \ldots, N-1)$.

Os coeficientes a0, ak e bk são obtidos, respectivamente, pelas seguintes expressões:

$$
\begin{aligned}
& a_{0}=\frac{1}{N} \sum_{i=1}^{N} f\left(t_{i}\right) \\
& a_{k}=\frac{2}{N} \sum_{i=1}^{N} f\left(t_{i}\right) \cos \left(k \omega t_{i}\right) \\
& b_{k}=\frac{2}{N} \sum_{i=1}^{N} f\left(t_{i}\right) \operatorname{sen}\left(k \omega t_{i}\right)
\end{aligned}
$$

A amplitude (ck) e o ângulo de fase ( $\varphi$ k) dos harmônicos são dados, respectivamente, por: 
$c_{k}=\sqrt{a_{k}^{2}+b_{k}^{2}}$

$\varphi_{k}=\arctan \left(\frac{b_{k}}{a_{k}}\right)$

No caso especifico do presente trabalho, $\mathrm{f}(\mathrm{ti})$ é o índice de umidade efetivo Im estimado ano a ano de 1961 a 2010 para São Gabriel da Cachoeira e Parintins e de 1971 a 2010 para Manicoré e será analisada a possibilidade da variação climática de tais localidades se repetirem no decorrer do tempo.

\section{Resultados e Discussão}

\section{Climatologia}

Neste tópico, buscou-se realizar a avaliação climatológica utilizando os dados do Instituto Nacional de Meteorologia (INMET) de temperaturas médias do ar mensais e anuais e acumulados mensais e anuais de chuva para as três localidades focos do estudo. Para isto, foram considerados tais dados para o período compreendido entre 1961 e 1990, que é o período recomendado pela OMM para elaboração da primeira norma climatológica.

\section{Análise do regime térmico}

A temperatura média anual no município de São Gabriel da Cachoeira, no período abordado nessa análise, é de $25,6^{\circ} \mathrm{C}$, que em comparação com as outras duas localidades de estudo, apresentam os menores valores de médias, com menor média nos mês de julho, cujo valor é $24,7^{\circ} \mathrm{C}$ e a maior média, no mês de fevereiro, de 26,1 $1^{\circ} \mathrm{C}$. Pela análise da Figura 2, observa-se que, nesta localidade, existe um período mais frio que se estende do mês de maio a agosto, e por outro lado, há um período mais quente compreendido entre os meses de outubro a março.

De outro modo, os dados do município de Parintins, em comparação com as outras duas localidades, apresentam os maiores valores de temperaturas médias, com média anual de $27,2^{\circ} \mathrm{C}$. A menor média acontece no mês de fevereiro, com valor de $26,4^{\circ} \mathrm{C}$ e a maior média em outubro, e tem valor de $28,5^{\circ} \mathrm{C}$. Ainda pela análise da figura, verifica-se que o período mais quente está compreendido entre agosto e dezembro e o período mais frio não tão bem definido, mas compreendido entre janeiro e março, ou seja, verifica-se que a marcha anual das temperaturas médias mensais de Parintins, segue o comportamento da configuração média mensal da precipitação.

Por outro lado, o município de Manicoré, ainda comparando os dados de temperaturas médias com os das outras duas localidades, teve valores intermediários, menores que os valores de Parintins e maiores que os de São Gabriel da Cachoeira. Pode-se dizer ainda que a variação anual da temperatura média em Manicoré é baixa, ou seja, não existem períodos mais frios ou quentes bem definidos. As médias mensais estão bem próximas da média anual, que é de $26,2^{\circ} \mathrm{C}$. Ainda assim, é possível observar os valores de menor média, em fevereiro, de $25,8^{\circ} \mathrm{C}$, e de maior média de $26,9^{\circ} \mathrm{C}$ em outubro.

Tabela 2 - Dados das temperaturas médias mensais do ar e médias anuais para os municípios de Manicoré, Parintins e São Gabriel da Cachoeira - AM no período de 1961 a 1990.

\begin{tabular}{|cccc|}
\hline & \multicolumn{3}{c|}{ Municípios } \\
\cline { 2 - 4 } & Manicoré & Parintins & São Gabriel da Cachoeira \\
\hline Meses & & 26,7 & 25,9 \\
\hline Janeiro & 25,8 & 26,7 \\
Fevereiro & 25,8 & 26,4 & 26,1 \\
Março & 26,1 & 26,6 & 26,0 \\
Abril & 26,3 & 26,7 & 25,8 \\
Maio & 25,9 & 26,7 & 25,4 \\
Junho & 26,0 & 26,8 & 24,9 \\
Julho & 26,1 & 26,8 & 24,7 \\
Agosto & 26,7 & 27,7 & 25,2 \\
Setembro & 26,7 & 28,2 & 25,7 \\
Outubro & 26,9 & 28,5 & 26,0 \\
Novembro & 26,7 & 28,3 & 26,0 \\
Dezembro & 26,2 & 27,4 & 25,9 \\
\hline Média anual & $\mathbf{2 6 , 2}$ & $\mathbf{2 7 , 2}$ & $\mathbf{2 5 , 6}$ \\
\hline
\end{tabular}




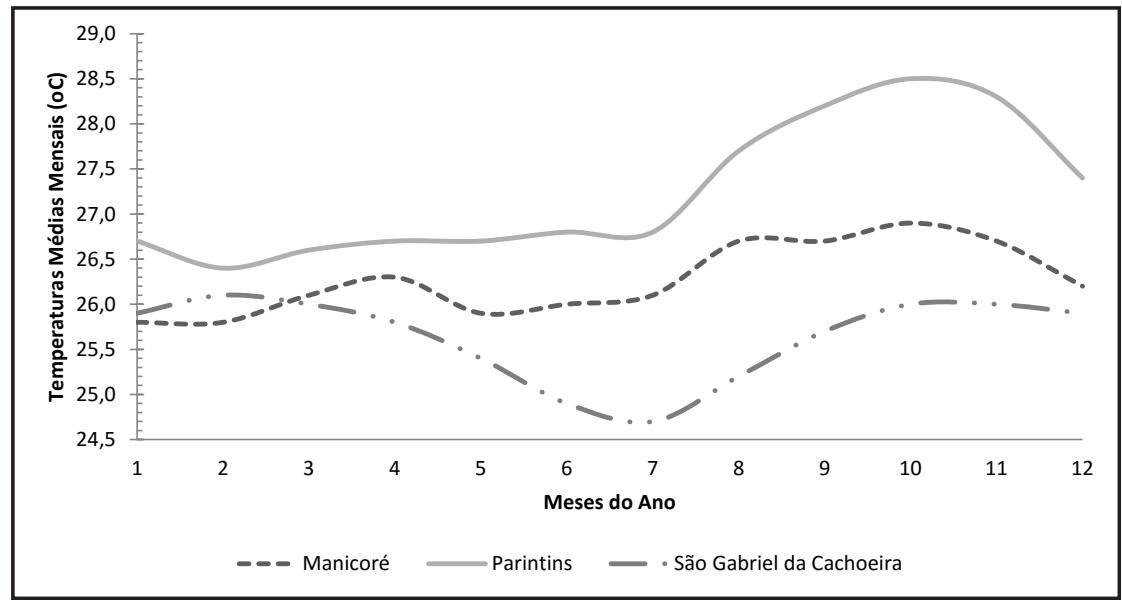

Figura 2 - Climatologia (1961-1990) das variações mensais das temperaturas médias para os municípios de Manicoré, Parintins e São Gabriel da Cachoeira - AM.

\section{Análise do regime de chuvas}

A partir da Figura 3 é possível analisar a climatologia mensal da precipitação para o período supracitado.

O maior acumulado de precipitação anual, comparando-se as três localidades, é observado no município de São Gabriel da Cachoeira, 2934,0 mm/ano de chuva. Os valores mensais desta localidade não apresentam grande variabilidade sazonal, pois para todos os meses do ano a precipitação total média mensal está próxima da média mensal anual, ou seja, isso significa que São Gabriel da Cachoeira não tem um período seco ou chuvoso bem definido. O maior acumulado mensal de precipitação é observado no mês de maio, $325,6 \mathrm{~mm} /$ mês e o menor acumulado mensal em outubro, e tem valor de 180,1 mm/mês.

Em oposição, os dados do município de Parintins apresentam os menores valores acumulados de precipitação anual, em comparação aos outros municípios. No período da análise, o acumulado anual de precipitação desta localidade é de 2302,2 mm/ano de chuva. O menor acumulado de chuva aconteceu no mês de setembro, cujo valor é de $58,5 \mathrm{~mm} / \mathrm{mês}$ e o maior acumulado, no mês de março, de $324,2 \mathrm{~mm} / \mathrm{mês}$. Da análise da Figura 3 , observa-se que existe um período seco que se estende do mês de julho a novembro. Por outro lado, há um período chuvoso compreendido entre os meses de dezembro a maio.

Ademais, ainda comparando as três localidades, o município de Manicoré apresentou valor de acumulado anual de chuva menor que São Gabriel da Cachoeira e maior que Parintins, alcançando um acumulado anual de $2699,2 \mathrm{~mm} / \mathrm{ano}$ de chuva. É a localidade onde se é mais fácil observar períodos chuvosos e secos mais bem

Tabela 3 - Dados dos acumulados mensais de chuva e acumulado anual para os municípios de Manicoré, Parintins e São Gabriel da Cachoeira - AM no período de 1961 a 1990.

\begin{tabular}{|cccc|}
\hline & \multicolumn{3}{c|}{ Municípios } \\
\cline { 2 - 4 } & Manicoré & Parintins & São Gabriel da Cachoeira \\
\hline Meses & \multicolumn{3}{c|}{} \\
\hline Janeiro & 334,7 & 237,5 & 286,4 \\
Fevereiro & 367,9 & 321,9 & 231,8 \\
Março & 293,5 & 324,2 & 241,7 \\
Abril & 338,8 & 308,4 & 294,1 \\
Maio & 222,1 & 262,9 & 325,6 \\
Junho & 107,7 & 203,7 & 285,8 \\
Julho & 74,7 & 132,9 & 247,6 \\
Agosto & 75,5 & 76,1 & 193,7 \\
Setembro & 143,7 & 58,5 & 194,2 \\
Outubro & 223,8 & 76,1 & 180,1 \\
Novembro & 231,7 & 105,7 & 191,4 \\
Dezembro & 285,2 & 194,3 & 261,9 \\
\hline Acumulado anual & $\mathbf{2 6 9 9 , 2}$ & $\mathbf{2 3 0 2 , 2}$ & $\mathbf{2 9 3 4 , 0}$ \\
\hline
\end{tabular}




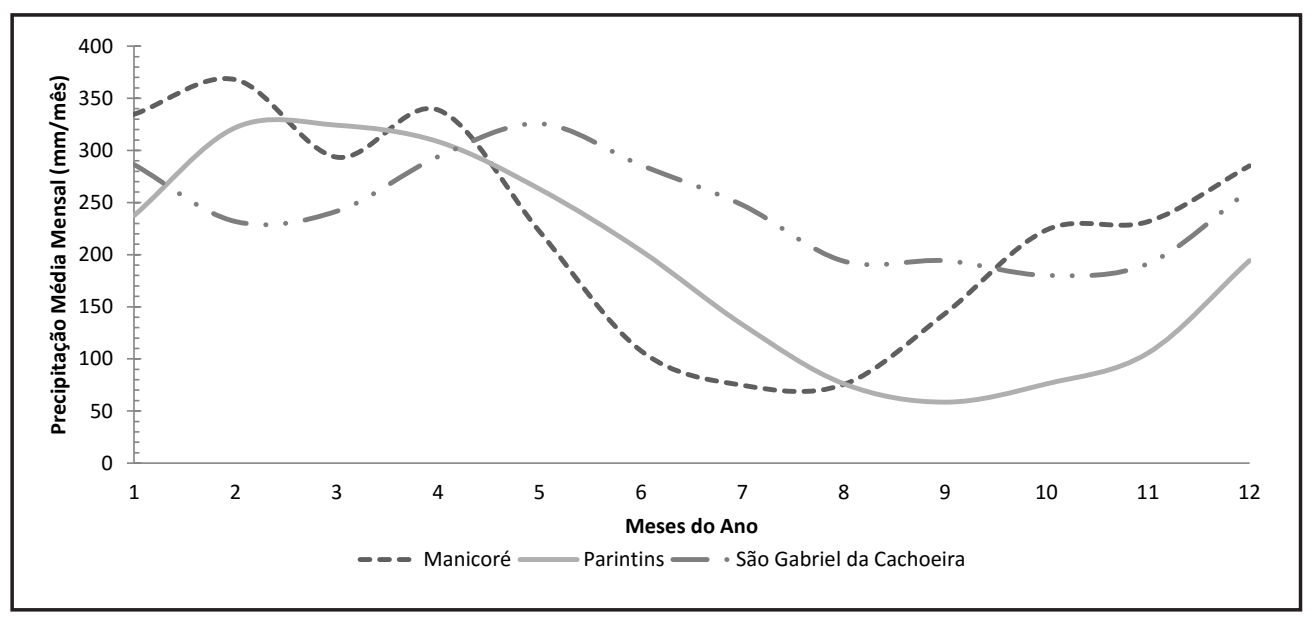

Figura 3 - Climatologia (1961-1990) dos acumulados mensais de chuva para os municípios de Manicoré, Parintins e São Gabriel da Cachoeira - AM.

definidos. O primeiro (chuvoso) ocorre entre os meses de outubro e maio, sendo que o mês de março apresenta um decréscimo no acumulado de chuva, ou seja, é um mês menos chuvoso em comparação com os meses adjacentes, fevereiro, com chuvas causadas pela Zona de Convergência do Atlântico Sul - ZCAS, e abril, com chuvas causadas pela Zona de Convergência Intertropical - ZCIT. Já o segundo (seco) está compreendido entre os meses de junho a setembro. $\mathrm{O}$ maior acumulado de chuva acontece no verão do Hemisfério Sul, no mês de fevereiro e alcança valores de $367,9 \mathrm{~mm} / \mathrm{mês}$ de chuva. O menor acumulado ocorre no inverno, no mês de julho, com valores de $74,7 \mathrm{~mm} / \mathrm{mês}$.

\section{Análise dos Índices de Aridez (Ia), Umidade (Iu)}

\section{e Efetivo de Umidade (Im)}

Os índices de umidade, aridez e efetivo de umidade servem de base para a classificação climática de Thornthwaite e Mather (1957). No presente trabalho estes índices são utilizados para análise da variabilidade interanual do clima.

Com base nisto, neste tópico busca-se analisar e classificar o clima das localidades em estudo utilizando o índice efetivo de umidade (Im) obtido pelo método de Thornthwaite e Mather (1957).

A Figura 4 apresenta os índices de aridez (Ia), umidade (Iu) e efetivo de umidade (Im) para o município de São Gabriel da Cachoeira - AM e linha de tendência para o Im para o período de 1961 a 2010. Pelo gráfico do Ia, observa-se que, basicamente, os valores do índice compreendem uma faixa tal que $0,0 \leq \mathrm{Ia} \leq 7,7$. Este índice expressa a deficiência hídrica em percentagem da evapotranspiração potencial. Portanto, verifica-se que em São Gabriel da Cachoeira não ocorreu deficiência hídrica atmosférica no período analisado.

Iu e Im confundem-se, na Figura 4, devido aos baixos valores de Ia. O índice efetivo de umidade (Im) tem sido vastamente utilizado como classificador das regiões sujeitas aos processos de desertificação e savanização (Hare, 1987). Porém, como mencionado anteriormente, é um índice indicado para classificação de diversos tipos de clima (Tabela 1). Com base em Im (Figura 4) verifica-se que São Gabriel da Cachoeira apresenta grande variabilidade interanual do clima. Existem anos em que Im alcança valores de tal modo que $\mathrm{Im}>100$, como por exemplo, 1967 (127,3), 1971 (124,6), entre outros. Pelo sistema de classificação climática, utilizado neste estudo, nesses anos, o município apresentou clima hiperúmido A. Por outro lado, há anos em que $\operatorname{Im}<40$, o que dá a classificação de clima úmido B1, como é o caso do ano de $2003(33,9)$. Os valores de Im dos outros anos estão compreendidos dentro desta faixa, $33,9 \leq \operatorname{Im} \leq 127,3$. A maior frequência de valores está entre $40 \leq \operatorname{Im} \leq 80$, o que dá uma classificação de clima úmido B4 e úmido B3. Tal variação mostra que o município de São Gabriel da Cachoeira experimenta forte dinâmica no clima ao longo do tempo, com alternância de diferentes regimes climáticos, variando de clima úmido B1, a clima hiperúmido A. Entretanto, o Im não apresentou tendência significativa ao longo da série, portanto, não ocorreu mudança no clima de São Gabriel da Cachoeira nos últimos cinquenta anos. Foram observadas apenas as variabilidades climáticas.

A Figura 5 representa os índices de aridez (Ia), umidade (Iu) e efetivo de umidade (Im) para o município de Parintins - AM e linha de tendência para o Im para o período de 1961 a 2010. Diferentemente do município de São Gabriel da Cachoeira, as curvas dispostas no gráfico são bem diferentes entre si. Para o índice de aridez, os valores de Ia compreendem a faixa que vai de 18,7 a 54,4. Comparando com a localidade anterior, pode-se dizer que esta é uma região menos úmida que São Gabriel da Cachoeira.

Apesar de Iu e Im não apresentarem valores parecidos, suas curvas estão dispostas, basicamente, no mesmo padrão de evolução. Com base na análise de 


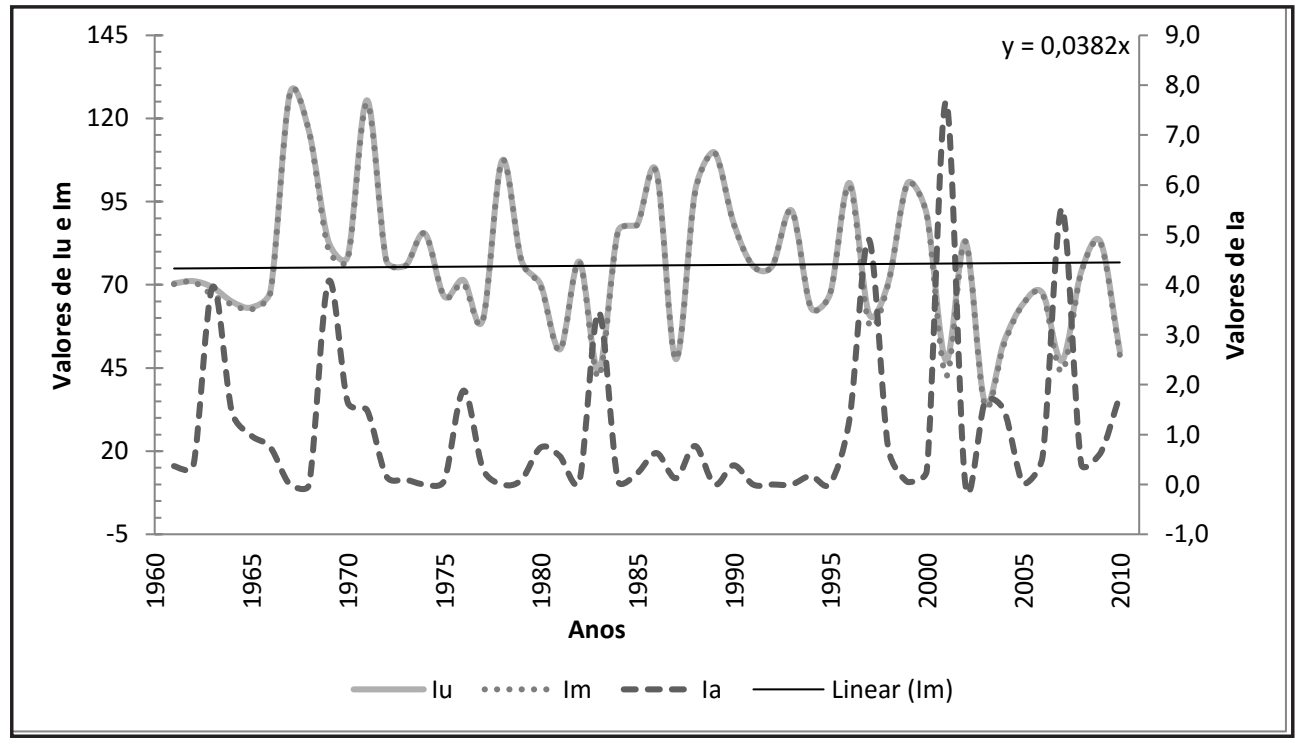

Figura 4 - Índices de aridez (Ia), umidade (Iu) e efetivo de umidade (Im) para o município de São Gabriel da Cachoeira - AM e linha de tendência para o Im compreendidos no período de 1961 a 2010.

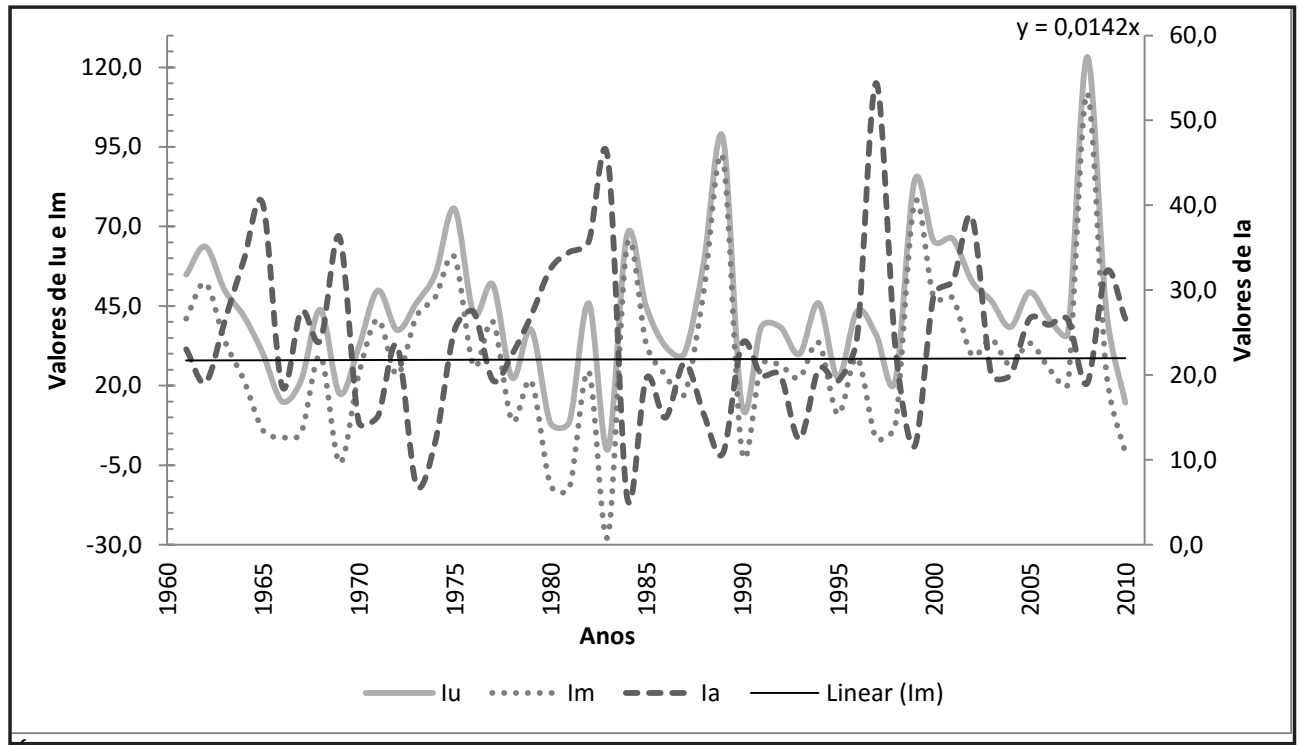

Figura 5 - Índices de aridez (Ia), umidade (Iu) e efetivo de umidade (Im) para o município de Parintins - AM e linha de tendência para o Im compreendidos no período de 1961 a 2010.

Im, em determinados anos, o índice de umidade efetivo apresenta valores $-27,3 \leq \operatorname{Im} \leq 111,9$. A maior frequência de valores está entre 34,6 (2003) e 20,6 (2007), o que dá a característica de clima úmido B1. Porém, como já falado, existem anos que foram caracterizados por valores bem baixos, $\mathrm{Im}=-27,3$ (1983), classificando o clima como semiárido e também anos que foram caracterizados por valores mais elevados, $\mathrm{Im}=111,9$ (2008), dando a classificação de clima hiperúmido. Esta variabilidade interanual do clima mostra que o município de Parintins também experimenta uma forte dinâmica no clima ao longo do tempo, existindo intensa alternância de diferentes regimes climáticos, que varia de clima semiárido D, a clima hiperúmido A. Assim como em São Gabriel da Cachoeira, não foi observada tendência de longo prazo no índice Im. Isto mostra que não ocorreu mudança climática em Parintins, pois se observou apenas variabilidade interanual do clima.

A Figura 6 apresenta os gráficos dos índices de aridez (Ia), umidade (Iu) e efetivo de umidade (Im) para o município de Manicoré - AM e linha de tendência para o Im no período de 1971 a 2010. Através de Ia, observa-se que, basicamente, os valores do índice compreendem uma faixa tal que $0,7 \leq$ Ia $\leq 24,1$.

O índice de umidade, Iu, representa o excesso hídrico expresso em percentagem da necessidade que é representada pela evapotranspiração potencial. Este índice, nessa localidade, apresentou valores entre 8,7 e 100,3, sendo que grande parte dos valores está acima de 10, ou seja, em geral, predomina excesso de água no solo. 


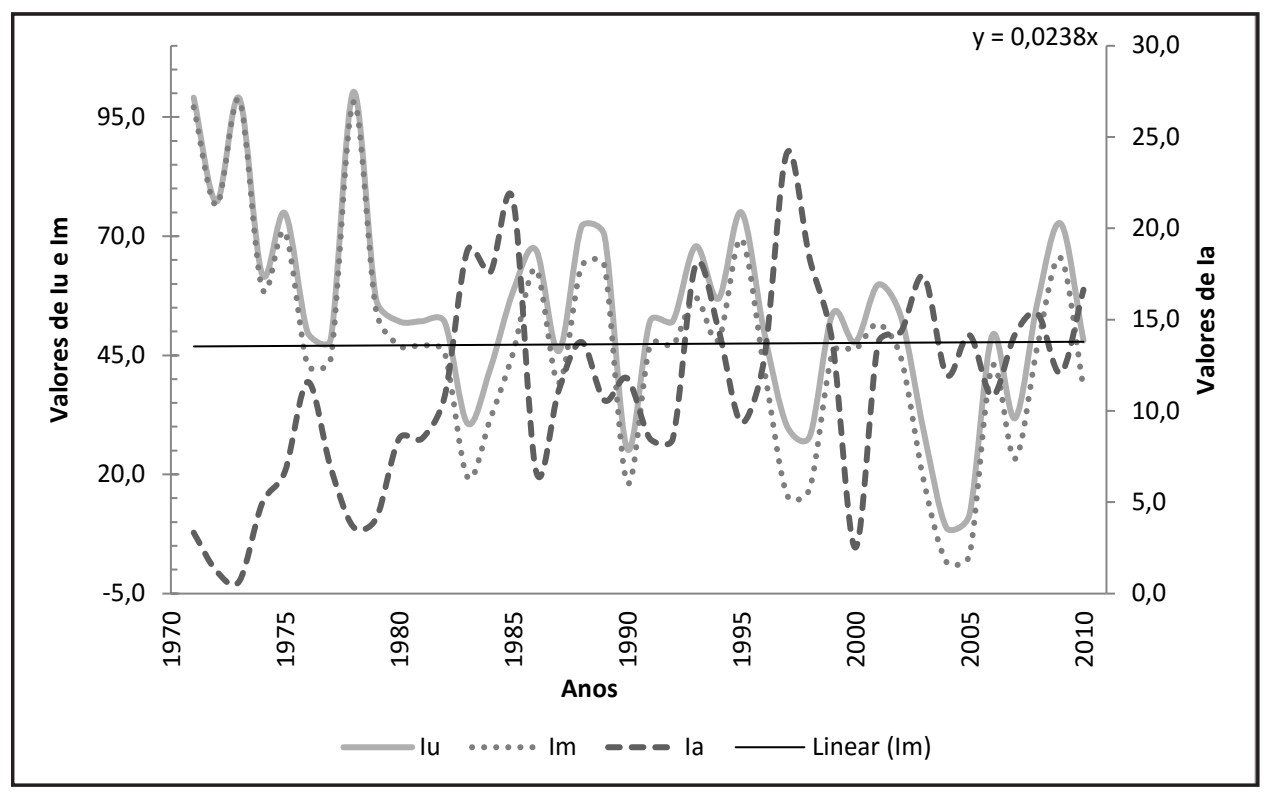

Figura 6 - Índices de aridez (Ia), umidade (Iu) e efetivo de umidade (Im) para o município de Manicoré - AM e linha de tendência para o Im compreendidos no período de 1971 a 2010.

O índice de umidade efetivo é função dos índices de aridez e de umidade, sendo que o índice de aridez tem um menor peso no cálculo. Através dele é que são classificados os tipos climáticos. Em Manicoré, predominam os climas: úmido B2 (42,3 (1996) $\leq \operatorname{Im} \leq 59,0$ (1974)); úmido B3 (63,1 (1986) $\leq$ Im $\leq 76,5$ (1972)); e sub-úmido úmido C2 (1,6 (2004) $\leq \operatorname{Im} \leq 19,4$ (1983)). Porém, os valores gerais deste índice estão compreendidos entre 1,6 e 98,6. Sendo assim, no geral, a localidade apresentou anos em que tinha características clima úmido B4 a sub-úmido úmido C2, ou seja, entre as três localidades foi a que apresentou a menor variabilidade interanual do clima. Assim, como nas demais localidades não foi verificado tendência de longo prazo de Im em Manicoré, ou seja, não se verificou mudanças climáticas em Manicoré nos últimos cinquenta anos, apenas variabilidade interanual do clima.

Ressalta-se que nas três localidades não foram observadas tendências de diminuição ou aumento de Im, ou seja, não ocorreram mudanças no clima. Este resultado difere dos de Santos et al. (2012) e Cutrim et al. (2000) que encontraram aumento da precipitação em Manaus. Os nomes e endereços informados nesta revista serão usados exclusivamente para os serviços prestados por esta publicação, não sendo disponibilizados para outras finalidades ou à terceiros.

\section{Análise dos harmônicos de Fourier}

Os Harmônicos de Fourier foram utilizados neste estudo para medir a frequência com que o índice efetivo de umidade se repete ao longo dos anos.

Para os harmônicos de Fourier de Im apresentado na Figura 7 para São Gabriel da Cachoeira, existem dois máximos do índice. O primeiro máximo, no harmônico 2 , informando que a cada vinte e cinco anos haverá um valor de máximo ou mínimo de Im. O segundo máximo, no harmônico 14, dá a informação de que a cada três anos também haverá um valor de máximo ou mínimo para o índice em questão. Existem outros pontos secundários observados mais abaixo que esses dois. O primeiro destes, no harmônico 5, mostra que a cada dez anos haverá valor máximo ou mínimo do índice efetivo de umidade. Por fim, o último ponto mais significativo para essa análise, no harmônico 23, haverá um valor de máximo de Im a cada dois anos. Dessa forma, pode-se afirmar que para o índice efetivo de umidade, observou-se oscilações interdecadais de 25 e 10 anos e interanuais de 3 e 2 anos . As razões para estas oscilações, possivelmente, estão relacionadas com as oscilações interdecenais do Pacífico (Oscilação Decenal do Pacífico) e do Atlântico (Oscilação Multidecenal do Atlântico). Enquanto, as oscilações interanuais estão relacionadas com os eventos de El Niño, La Niña e gradiente de anomalia de TSM no Atlântico.

Para localidade de Parintins, as amplitudes dos harmônicos de Fourier do índice Im, são mostradas na Figura 8, observa-se que existem apenas dois máximos significativos de maiores valores das amplitudes. $\mathrm{O}$ primeiro máximo, no harmônico 4, dando a informação de que a cada 12,5 anos (de 12 a 13 anos) haverá um valor de máximo ou mínimo de $\mathrm{Im}$. O segundo pico, no harmônico 21, indicando que a cada dois anos também haverá um valor de máximo ou mínimo para o índice. Não existem outros significativos que indiquem forte variabilidade a repetição do ciclo. Dessa forma, pode-se afirmar que para o índice efetivo de umidade, existe uma oscilação interdecenal de 12 a 13 anos e uma oscilação interanual de dois anos. As razões para estas oscilações são semelhantes às de São Gabriel da Cachoeira. 


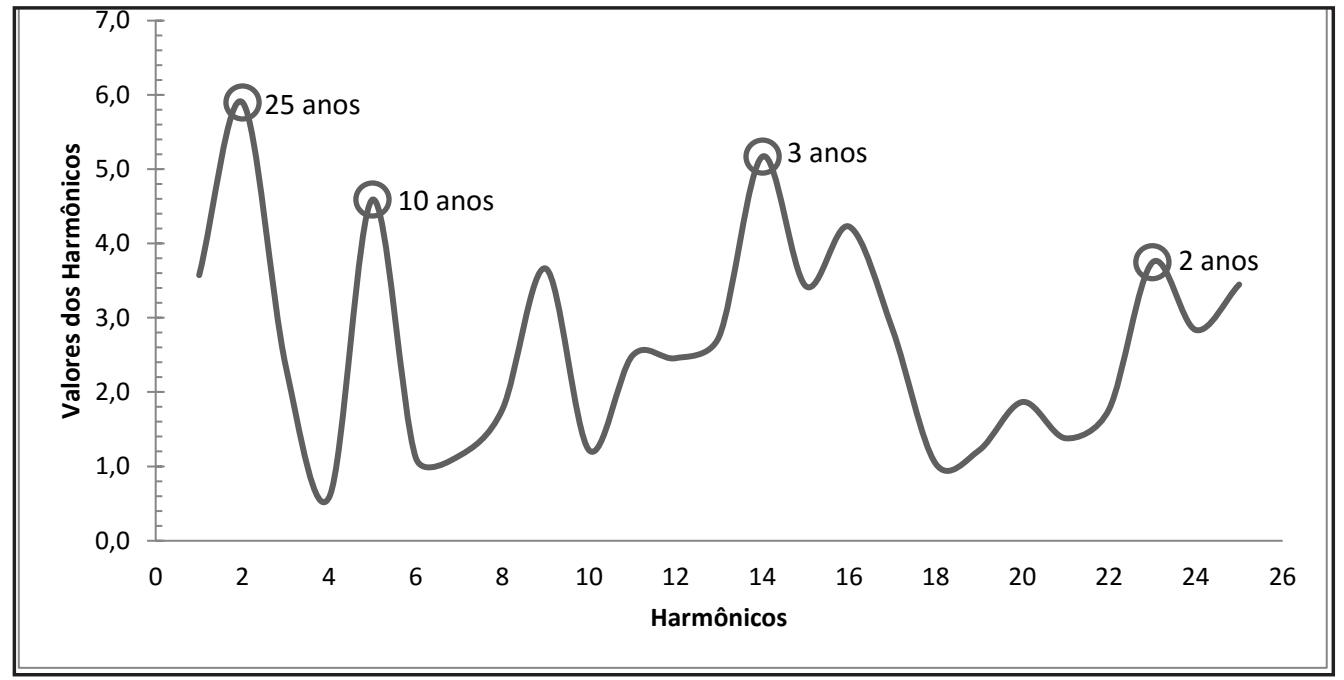

Figura 7 - Harmônico de Fourier do Índice Efetivo de Umidade (Im) para a localidade de São Gabriel da Cachoeira - AM.

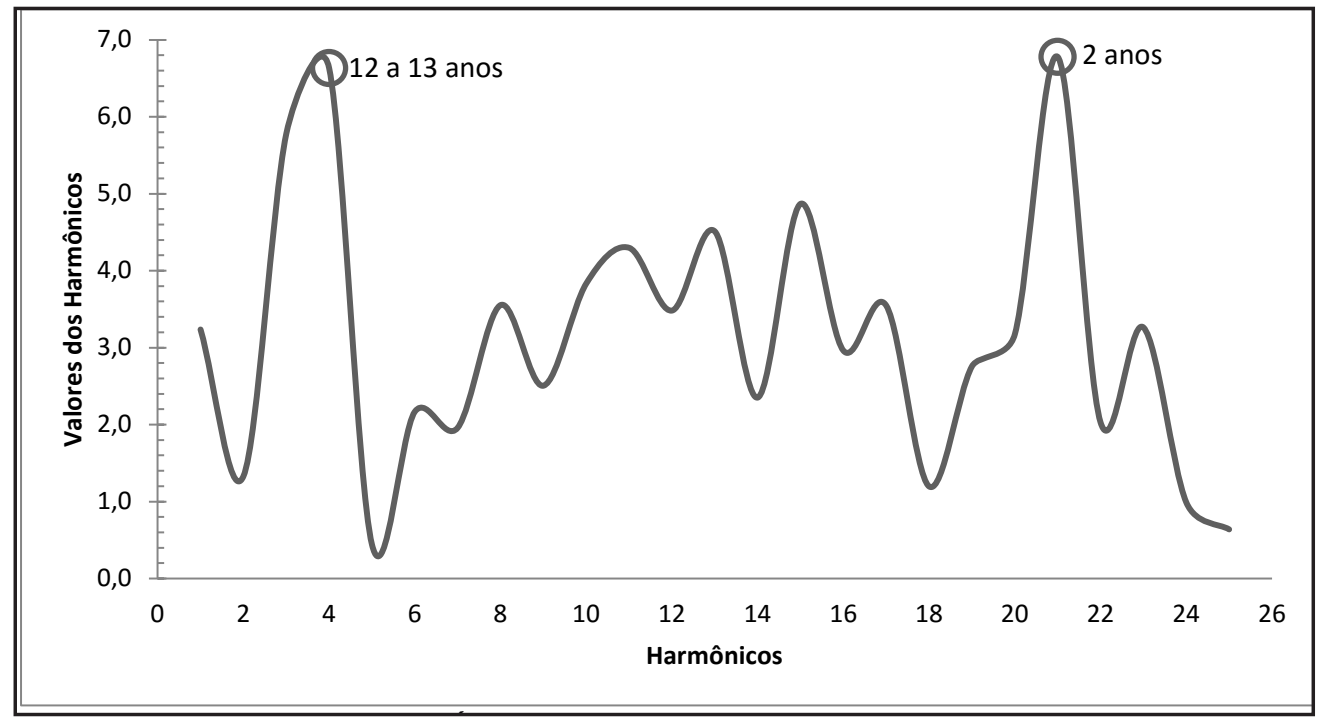

Figura 8 - Harmônico de Fourier do Índice Efetivo de Umidade (Im) para a localidade de Parintins - AM.

Para o índice efetivo de umidade, Im, observado em Manicoré (Figura 9), existem um maior valor predominante e outros dois menores. O primeiro, no harmônico 2, dá a informação de que a cada vinte anos haverá um valor de máximo ou mínimo de Im. O segundo pico, no harmônico 6, indica que a cada sete anos, aproximadamente, também haverá um valor de máximo ou mínimo para o índice Im. Há ainda, no harmônico 12, a informação de que a cada três anos também há a repetição do ciclo. Existem outros pontos secundários observados mais abaixo que esses. O primeiro destes, no harmônico 18, mostra que a cada dois anos haverá valor máximo ou mínimo do índice efetivo de umidade. Por fim, o último ponto mais significativo para essa análise, no harmônico 16, haverá um valor de máximo de Im a cada dois anos e meio. Dessa forma, pode-se afirmar que, para o índice efetivo de umidade, existe uma oscilação interdecenal de vinte anos e quatro oscilações interanuais de sete, três, dois e dois anos e meio. Além dessas, são também observadas outras oscilações menos significativas. As causas das oscilações interdecenal e interanuais são as mesmas das de São Gabriel da Cachoeira.

Finalmente, de uma maneira geral, observa-se que as três localidades apresentam oscilações interdecenais do índice Im, ou seja, variabilidade interdecenal do clima, possivelmente, decorrentes da oscilação decenal do Pacífico e da oscilação Multidecenal do Atlântico, e oscilações interanuais provavelmente relacionadas com os eventos de El Niño, La Niña e gradiente de anomalia de TSM no Atlântico. 


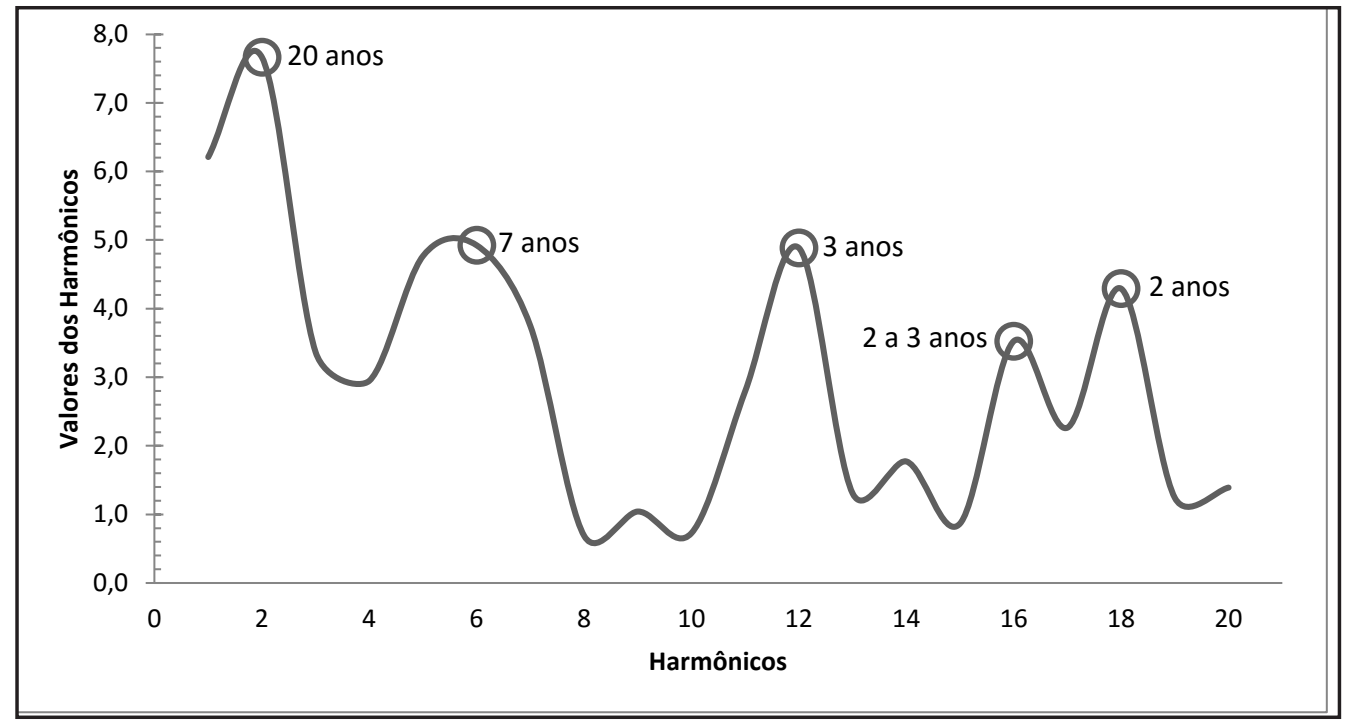

Figura 9 - Harmônico de Fourier do Índice Efetivo de Umidade (Im) para a localidade de Manicoré - AM.

\section{Conclusões}

De acordo com os objetivos propostos e os resultados obtidos, chegou-se à conclusão de que as localidades estudadas experimentam intensa variabilidade interanual do clima. Na região onde o município de São Gabriel da Cachoeira está localizado, mais a oeste do estado do Amazonas, foi observada a menor variabilidade do clima, o que já era esperado, visto que existe a influência direta do clima da Floresta Amazônica. O fato do índice de aridez não ter sido elevado fez com que a localidade apresentasse variabilidade de clima úmido a hiperúmido.

Por outro lado, o município de Parintins apresentou a maior variabilidade climática. A localização mais a leste, ou seja, apresentando uma menor influência do clima da Floresta Amazônica, pode ter sido a causa dessa maior flutuação, que vai de clima semiárido a úmido. Além disso, Manicoré apresentou variabilidade climática oscilando de clima sub-úmido úmido a úmido B4.

Pode-se ser conjecturado que a variabilidade interanual do clima observada nas três localidades seja decorrente dos eventos El Niño, La Niña e do gradiente de anomalia de TSM do Atlântico tropical.

Também foram observadas variabilidades interdecenal do clima, possivelmente relacionadas com as oscilações decenal do Pacífico e multidecenal do Atlântico.

Não se verificou mudanças climáticas em nenhuma dos três municípios.

\section{Agradecimentos}

A CAPES pela concessão da bolsa de Mestrado.

\section{Referências}

Budyko, M.I (1974). Climate and life. International geophysical series, v.18. San diego, CA: academic press. 508p.

Cutrim, E. M. C., Molion, 1. B., Echet, d. (2000). Chuvas na Amazônia durante o século XX. Anais: XI Congresso Brasileiro de Meteorologia, Rio de Janeiro, 1327-1333.

Fearnside, P.M. (2006). Greenhouse gas emissions from hydroelectric dams: reply to rosa et al. Climatic change. 75(1-2): 103-109.

Freitas, F. C. L., Nascente, A. S., Sousa, F. L. (2013). População de plantas de milho consorciado com urochloa ruziziensis. Pesq. Agropec. Trop., Goiânia, v. 43, n. 1, p. 79.

Hare, F. K. (1977). Climate and desertification 63167. In: Desertificacion: its causes and consequences. Secretariat of the United Nations conference on desertification, nairobi. Pergamon press. Oxford. $448 \mathrm{p}$.

Hare, F. K. (1985). Sequia, Variacion climatica y desertificacion. Ginebra: Organizacion Meteorologica Mundial. 35p.

Krishan, A. (1980). Agroclimatic classification methods and their application to Índia. In: Climatic Classification: A consultant's meeting. Icrisat Center, Patancheru, India, 14-16. 
Oliveira, F. N. M., Araújo, R. L. C., Carvalho, J. S., Silva, C. L. (2006). Inferência de mudanças climáticas na região de Manaus (AM) usando dados geotermais e meteorológicos. Revista Brasileira de Geofísica, v. 24, n. 2, p. 169-187.

Quispe, D. P. (2013). Experimentos de sensibilidade sobre o Brasil em cenários de aquecimento global utilizando modelo climático regional. Dissertação (mestrado em meteorologia) - Instituto Nacional de Pesquisas Espaciais, São José dos Campos, 168 f.

Santos, C. A. C., Brito, J. I. B. (2007). Análise dos índices de extremos para o semiárido do Brasil e suas relações com TSM e IVDN. Revista Brasileira de Meteorologia, v. 22, n. 3, p. 303-312.

Santos, G. M., Alexandre, A., Southon, J. R., Treseder, K. K., Corbineau, R., Reyerson, P. E. (2012). Possible source of ancient carbono in phylotith concentrates from harvested grasses. Biogeosciences, 9, 1873-1874.

Thornthwaite, C. W., Mather, J. R. (1957). Instructions and tables for computing potential evapotranspiration and water balance. Publications in climatology, vol. 10, no. 3. Drexel Institute of Technology, centerton.

Thornthwaite, C.W. (1948). An approach toward a rational classification of climate. Geographical review, v.38, p.55-94.

Zektser, I.S., Loaiciga, H.A. (1993). Groundwater fluxes in the global hydrologic cycle: past, present and future. Journal of Hydrology, v.144, n.sf, p.405-427. 